\title{
Genome Editing Tools: Need of the Current Era
}

\author{
Sabin Aslam ${ }^{*}$, Sultan Habibullah Khan ${ }^{2}$, Aftab Ahmed ${ }^{2}$, Abhaya M. Dandekar ${ }^{3}$ \\ ${ }^{1}$ Center of Agricultural Biochemistry and Biotechnology, University of Agriculture, Faisalabad, Pakistan \\ ${ }^{2}$ Center of Advanced Studies in Agriculture and Food Security, University of Agriculture, Faisalabad, Pakistan \\ ${ }^{3}$ Department of Plant Sciences, University of California, Davis, CA, USA \\ Email: *sabinaslam@gmail.com, *sabaslam@ucdavis.edu
}

How to cite this paper: Aslam, S., Khan, S.H., Ahmed, A. and Dandekar, A.M. (2019) Genome Editing Tools: Need of the Current Era. American Journal of Molecular Biology, 9, 85-109.

https://doi.org/10.4236/ajmb.2019.93008

Received: January 25, 2019

Accepted: July 12, 2019

Published: July 15, 2019

Copyright $\odot 2019$ by author(s) and Scientific Research Publishing Inc. This work is licensed under the Creative Commons Attribution International License (CC BY 4.0).

http://creativecommons.org/licenses/by/4.0/

\begin{abstract}
Genome editing is considered as the most widely used approach of the present era. It had become a basic need of the current micro and molecular biological experiments. Gene engineering finds its widespread applications in medical, industry and agricultural sector. Unlike previous genetic engineering practices to insert or delete a part of genetic material at random place, genome editing allows the precise manipulation of DNA at a specific location. Zinc Finger Nucleases (ZFNs), Transcription Activator like Effector Nucleases (TALENs), Clustered Regularly Interspresed Short Palindromic repeats (CRISPR/Cas system) and meganucleases (recombinases) are the prime tools for editing an organism's genome. Genome editing tools have an advantage to selectively delete or to integrate specific genes at specific loci. Use of recombinases for specifying site has further reduced time to integrate genes site specifically. Site specific gene stacking by the use of recombinases coupled with ZFNs, TALENs, or CRISPR/Cas genes have paved new pathways to target genes site specifically and to improve germplasm in lesser time than conventional breeding approaches.
\end{abstract}

\section{Keywords}

CRISPR/Cas, Gene Stacking, Recombinases, TALENs, ZFNs

\section{Introduction}

A latest trend towards cultivation of genetically modified crops is the development of stacked characters. Plants with random stacked traits were previously made through conventional breeding. Stacking can be done by crossing transgenic plants carrying multiple transgenes. Some companies working with biotech crops are developing stacked-trait varieties with increased resistance to insects, herbicides and to some extent, weeds. New technologies for pyramiding 
different characters at a single transgene position, have been developed [1].

Engineered chromosomes with stable mitosis and meiosis can stack multiple traits [2]. Key steps for engineering chromosomes, including chromosomal ending by T-DNA, mediated telomere seeding and the formation of novel centromeres using fusion protein cenH3, have been accomplished. These steps help generate vigorous protocols for biotechnological applications by using site-specific recombination for targeted genome engineering to enhance production, although this technology is still in its infancy. The assortment of independent loci can be employed to conjoin transgenes into the genome. This is a conventional breeding technique that has long been used for various transgenic traits. As the loci of interest proliferate, a larger population is required to discover individuals with the preferred assortment of genetically modified or non-transgenic elite alleles [3].

Incorporating a modified gene into a commercial variety circumvents the need to introgress the engineered traits, but separate transformations with characterization of regulatory events are required. The difficulty of segregating genetically modified loci can be decreased by introducing multiple traits at the same time. Adding a new trait to a preexisting locus is a better strategy, if reengineering of previously introduced traits is not required. This is done by aiming a novel gene segment at a known genomic target using homology-directed repairing, host DNA sequence-based processes, or a site-specific recombination system. Gene pyramiding through site-specific recombination is a better option for introducing new DNA sequences [4].

Emerging technologies allow targeted genome editing in diverse systems through accurate manipulation of the genome in its natural context and gene addition at specific loci. It is achieved by combining specific protein domains, including ZFs and TALEs. Current improvements in these technologies have increased nuclease performance and allowed cost-effective genome editing. The technology is being exploited for pre-clinical and clinical gene therapies for many diseases [5].

Targeted genome engineering is an emerging field of research to improve resistance in crop plants [6]. Unlike conventional plant breeding and transgenic procedures, this technology offers new tools to engineer the genome at a specific target location [6]. Targeted genome engineering was first used in tobacco-five years after transgenic plants were achieved. Targeted genome engineering through homologous recombination was rate-compared to random insertion of the transgene, due to perception that targeted genome engineering was not achievable in higher plants. It took 25 years to develop the knowledge and techniques to perform targeted genome engineering in higher plants. The problem was resolved with the discovery of restriction endonucleases causing double-strand breaks at a specific site on DNA. This allowed gene targeting of higher plants, particularly after the introduction of zinc finger nucleases (ZFNs) in 2005. ZFNs provided tools for targeted genome engineering, including Transcription Activator-Like Effector Nucleases (TALENs), meganucleases and the Cluster Regu- 
larly Interspresed Short Palindromic Repeats (CRISPR/Cas) system [7].

In conjunction with conventional breeding, new biotechnological techniques provide an opportunity to improve agronomic traits in crops. Genome-editing tools like recombinases, ZFNs, TALENs and CRISPR/Cas9 could markedly improve crop biotechnology. Gene pyramiding at a specific location helps prolong resistance to various diseases. A brief overview of these approaches is given below.

\section{Recombinases}

Genome engineering with the help of recombinases is no longer a new approach. This technique is now at its third decade and recombinases can work in heterologous systems [8]. Site-specific recombinase technology studies the structure and function of genes. These recombinases bind DNA at a specific target site.

An early site-specific recombinase system is Cre/lox [9]. Cre recombinase requires two loxP DNA recognition sites to bind. As Cre recombinase is a form of type 1 topoisomerase, no cofactor is needed for its optimal functioning. The loxP recognition site has a specific sequence recognized by Cre recombinase only. When a cell expresses Cre recombinase with its specific loxP sites, recombination occurs. Cre recombinase cuts both DNA strands at a specific site defined by the orientation of LoxP site sequence. The relative alignment of the DNA recognition site controls the action of Cre recombinase. Site-specific recombinase technology is used to delete, insert or invert a specific sequence at a target site. A transgenic organism with Cre recombinase expressed by a tissue-specific promoter can be crossed to excise the gene present between two loxP sites. Targeted excision deletes the function of genes within specific tissues. Deletion of genes by site-specific recombinase technology is a particularly advantageous method of gene excision. Inversion phenomenon occurs due to the presence of LoxP sites in reverse orientation. When Cre recombinase causes recombination of invertly oriented LoxP site; it causes the inversion of the sequence flanked between two LoxP sites to $180^{\circ}$. Integration strategy is slightly different and is caused by most of the serine recombinases. Most serine recombinases work with att sites (attP: attachment site for phage and attB: attachment site for bacteria) present on two different DNA sequences. A serine recombinase causes recombination between its specific attP site and attB site and induces the integration of DNA sequence [9] (Figure 1).

The coded serine integrase Phageen combines DNA invertases and transposon resolvases that work on the specific DNA recognition sites attP and attB. High-order DNA coiling or accessory proteins are not required for proper function. Synapsis is required for correct pairing of DNA substrates [10]. Bxb1 specifically binds to attP and attB to produce the irreversible hybrid sites attL and attR. The structural domain of Bxb1 integrase, the uncommon ability of integrase to specifically bind DNA and protein analysis with transformed site-specificity depend on the altered DNA-integrase complex [10]. 
A Deletion of DNA Cassette

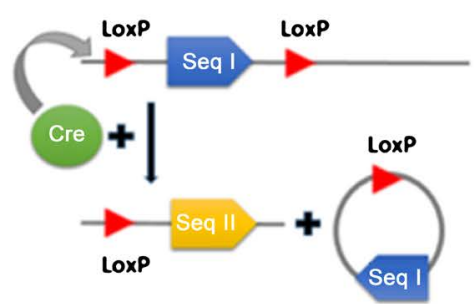

B Inversion of DNA Cassette

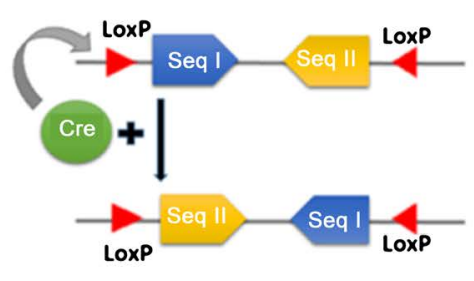

C Integration of DNA Cassette

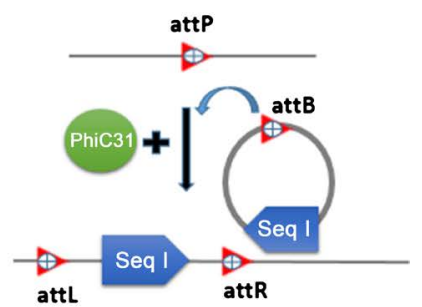

Figure 1. Recombinases in action.

Bxb1 integrase is an enzyme from the mycobacteriophage Mycobacterium smegmatis genome that inserts its DNA at the attB recognition site [11]. It uses a phage-encoded integrase and a phage attachment site (attP) to produce recombinant recognition sites attL and attR. It is a serine recombinase family member that accomplishes recombination with a short 50-bp sequence. It causes exchange of strands without high-molecular-weight substrates. A recombinase directionality factor $(\mathrm{RDF})$ expedites excision and integration of recombinase. The $\mathrm{RDF}$ of $\mathrm{Bxb} 1$ is an uncommon recombinase directionality factor that performs a double function by using discrete systems of integration and being conserved in the mycobacteriophage. It functions exclusively through direct interaction with complexes of integrase and DNA, it doesn't bind solely to DNA. This interaction depends on the target sequence having attP or attB DNA recognition sites [11].

PhiC31 integrase is an efficient recombinase for gene therapy that integrates novel genes at target sites in the mammalian genome with prolonged stability of the integrated transgene. The specific att integration site in mammalian cells is determined by the PhiC31 integrase. In vivo and in vitro recombinase activity has been observed in mammalian liver, muscle, eye, joint, skin keratinocyte, muscle precursor cell and $\mathrm{T}$ cell lines [12].

A dual function gene for site-specific recombination was made by fusing the coding regions of Cre and FLP recombinases [13]. Transgenic maize plants with fused Cre and FLP expression vectors were crossed with plants with the corresponding loxP or FRT sites. The plants of the first and second filial generations showed accurate excision of a gene flanked between the loxP and FRT sites. Recombination occurred in the F2 generation between non-recombined parts of FRT and Cre found during the F1 generation. A recombination product was found in the F3 generation, when the recombined product of F2 was crossed back to plants with FLP. Cre-mediated excision was analyzed using the fusion protein of FLP and Cre [13]. This recombination strategy could be helpful in genetic engineering of crop plants using FLP-FRT and Cre-loxP systems.

Site-specific recombination has been used in organisms like mouse. The utility of the Cre, Flp, Dre and phiC31 recombinases to introduce site-specific recombination was reviewed [14]. Precision engineering of the mouse genome used Flp-excision (FLEx) and recombinase-mediated cassette exchange (RMCE). A complete workflow technique following site-specific recombinase was described 
to generate a model mouse with specific characters, aiding cellular-level genome analysis [14].

Transgenic embryos of Xenopus laevis were made using phiC31 integrase [15]. The integrase helped bacteriophage phiC31 insert its whole genome into the host organism by catalyzing a recombination reaction between the attP attachment site on the phage and the attB attachment site on the bacterium. Integrase does not require sequence fidelity to recognize its target site and recombination reactions across attachment sites have high proficiency with no accessory factor required. Transgenes can be inserted between attachment sites or pseudo attachment sites in a range of organisms [15].

The two site-specific recombination systems FLP/FRT and Cre/loxP were studied in a hybrid clone of aspen [16]. A heat-inducible soybean promoter, Gmhsp 17.5-E. was excised using Cre and FLP recombination. Results were promising for the transfer of a specific gene to a specific target [16].

Site-specific recombination allows insertion of multiple transgenes into a single locus, removal of undesirable DNA and accurate insertion of a DNA sequence to a target site. Recombinases can also effectively insert DNA into non-nuclear targets such as plastids or mitochondria [17].

Cre recombinase was used for site-specific integration of DNA sequences into embryonic mouse stem cells [18]. Mutation events in the left and right elements (LE/RE) of lox-P sites enhanced integration, forming wild type and double-mutant sites. Double-mutant sites reduced the affinity of Cre recombinase for its attachment sites, leading to stable integration at recombination sites lox71 and lox66. High efficiency of mutant loxP sites was also observed in Escherichia coli. To estimate recombination efficiency, six right-element lox sites were compared with lox71 in embryonic stem cells with no significant difference in transformation efficiency among sites. The recombined product was stable in ES cells. More stable left and right elements of double mutant lox sites were produced from loxJTZ17 and loxKR3 than double mutant lox66/71. The integration and inversion reaction in embryonic stem cells resulted in much more stable mutant lox sites loxJTZ17 and lox KR33 [18].

Recombinase family is shown in Figure 2. Recombineering is an emerging term for site-specific genome engineering with recombinases [19]. A phage-derived, homology-directed repair pathway is used to recombine a donor DNA strand in the bacterial host's homologous sequence. With $\sim 4500$ bp homologous flanking regions, a RecA/Rad51-mediated homologous recombination pathway can insert a desired genome sequence into the genome of almost any cell type, although the lesser efficacy of native homologous recombination machinery limits the use of this technique without an efficient selection and DNA delivery method [19]. For now, it is an improved technique for targeted genome engineering [20] [21] [22].

The importance of editing intricate characters was studied by inserting new genes into plants transformed with more than one gene [23]. Gene pyramiding streamlines plant breeding strategies. Marker gene recycling and gene integration 


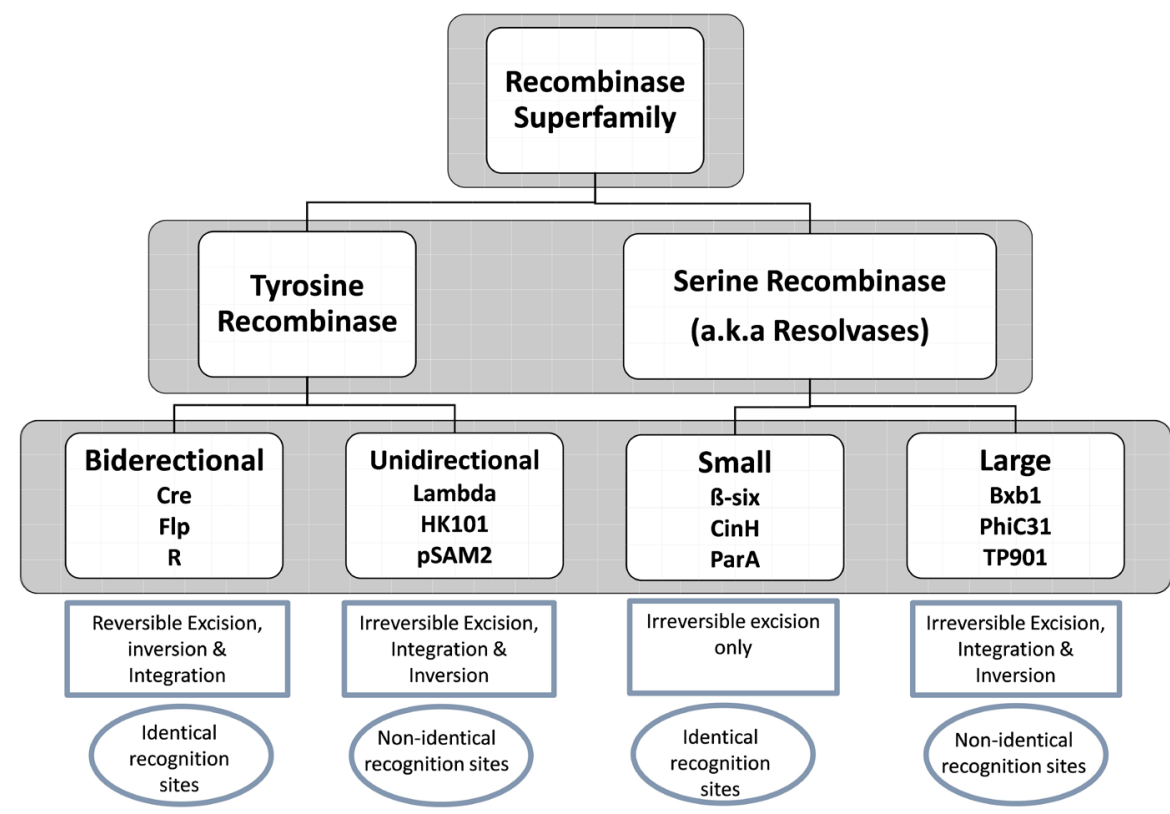

Figure 2. Recombinase family. (Source: Wang et al., 2011).

at a specified site are important parameters for site-specific gene stacking. Double-strand breaks induced by restriction endonucleases make targeted gene insertions more difficult. Targeted gene integration can be accomplished proficiently using the Cre-loxP recombination system. However, using the Cre-loxP recombination system in gene stacking is complicated by two loxP sites at the cis position, which can reverse recombination efficiency. The efficiency of Cre-loxP recombination could be increased by placing one of the cis-positioned loxP sites in the marker gene [23].

\section{Zinc Finger Nucleases (ZFNs)}

ZFNs target specific DNA sequences within the genome of many organisms. An engineered DNA-binding domain and Fok1 type II restriction endonuclease cleavage domain combine to form a ZFN (Figure 3). At the cleavage site of the nuclease domain, dimerization of the restriction endonuclease domain leaves a spacer sequence of five to six base pairs.

\section{1) DNA-Binding Domain}

The DNA-binding domain of a single ZFN is composed of three to six individual repeats of zinc fingers. Each zinc finger repeat recognizes a three base pairs DNA

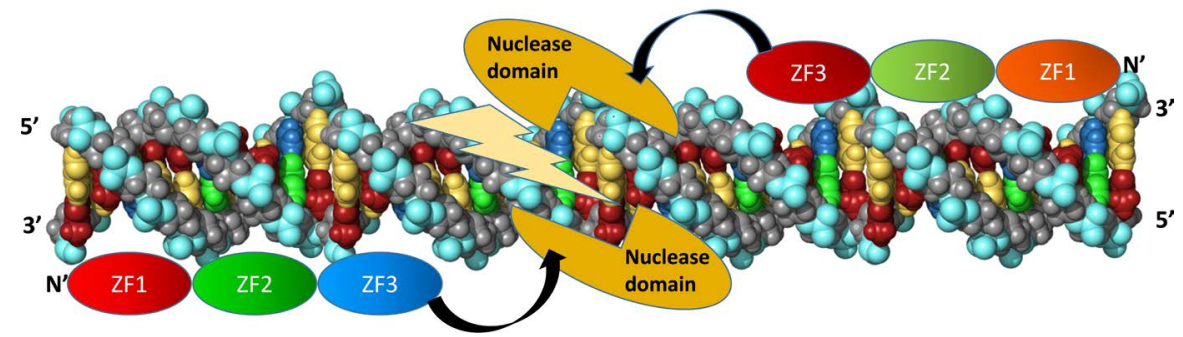

Figure 3. Zinc finger nucleases. 
sequence. A combination of three to four zinc fingers can perfectly recognize a nine to 12 base pairs DNA sequence. Zinc finger arrays can be designed to target specific DNA sequences. Yeast one and two hybrid systems, bacterial one and two hybrid systems, phage display or mammalian cells are used to select specific proteins among a pool of zinc finger arrays that bind the target DNA sequence. A recent method for selecting ZFN arrays using a bacterial two-hybrid system is called "OPEN" Oligomerized Pool Engineering [24]. In OPEN, each zinc finger is pre-selected to bind a specific DNA triplet. A second selection step identifies a combination of three zinc fingers binding to a nine base pairs sequence. This offers an alternative to commercial purchase of engineered nucleases for designing ZFN arrays [25] (Figure 4(a)).

\section{2) DNA-Cleavage Domain}

FokI type IIs restriction endonuclease is used for the cleavage domain of ZFNs [26]. These cleavage domains work in tandem to cleave the site defined by the DNA binding domain [27]. The FokI cleavage domain is attached to the C-terminus of the DNA binding domain to form a ZFN. The two ZFNs bind to two DNA strands in opposite orientations to cleave the spacer region defined by the DNA binding domain. The 5' edge of the DNA binding site defines a five to seven base pair spacer region between the DNA binding and cleavage domains [28] (Figure 4(b)).

ZFN technology as an emerging gene-targeting procedure could be used to engineer specific loci of many organisms [29]. The applications of ZFNs for genome engineering emerged as DNA scissors [30]. These engineered DNA scissors have precisely manipulated genetic information in several plant and animal species. ZFN technology is an emerging approach for genome engineering in the context of ever-expanding genetic information from different organisms [30] (Table 1).

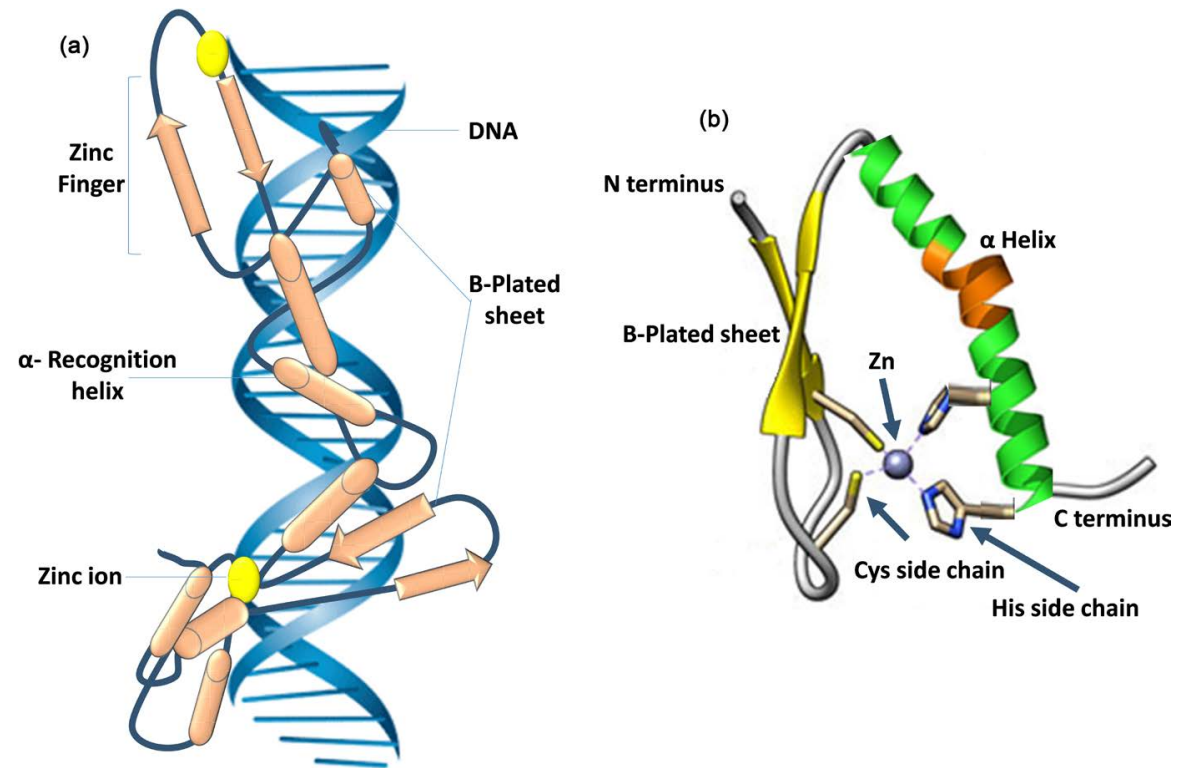

Figure 4. Zinc finger nucleases. (a) DNA binding domain; (b) DNA cleavage domain. 
Table 1. Applications of ZFNs.

\begin{tabular}{cccc}
\hline Organism & Gene(s) & Editing & Reference \\
\hline Zebrafish & ------ & Targeted knockout & {$[29]$} \\
Mammals & Stem cells & Gene therapy & {$[56]$} \\
Maize & IPK1 & Insertional disruption & {$[57]$} \\
Tobacco & Endochitinase & Integration & {$[58]$} \\
Tobacco & SurA \& SurB & Gene targeting & {$[59]$} \\
Rat & M (IGM) \& Rab38 & Targeted mutagenesis & {$[60]$} \\
Sea Urchin & HepHesC & Deletion \& insertion & {$[61]$} \\
Silkworm & BmBLOS2 & Targeted mutagenesis & {$[62]$} \\
Arabidopsis & ADH1 \& TT4 ZFN & Targeted mutagenesis & {$[35]$} \\
Arabidopsis & ABI4 & Site directed mutagenesis & {$[63]$} \\
Mice & H3.3 & Endogenous tagging & {$[64]$} \\
Soybean & DCL4a \& DCL4b & Targeted mutagenesis & {$[65]$} \\
Frog & Noggin & Targeted mutagenesis & {$[66]$} \\
Rabbit & M (IGM) locus with exon 1 \& 2 & Targeted replacement & {$[67]$} \\
Pigs & GGTA1 & Biallelic knockout & {$[68]$} \\
Mouse & F9 & In vivo gene editing & {$[69]$} \\
Cattle & BLG & Gene modification & {$[70]$} \\
Fruit fly & ben-1 & Targeted mutagenesis & {$[71]$} \\
Human & CCR5 & Gene editing & {$[72]$} \\
\hline
\end{tabular}

$\mathrm{Cys}_{2}-\mathrm{His}_{2}$ zinc-finger protein domains are among the most important DNA binding domains in eukaryotes and the second-most repeated encoded protein domains in humans [31]. Each zinc finger is composed of $\sim 30$ amino acids with a conserved $\beta \beta \alpha$ configuration. Amino acids on the surface of the $\alpha$-helix occasionally bind to three base pairs of the major groove of DNA with high selectivity [31]. More than three zinc finger domain arrays are required to specifically recognize a target DNA sequence, leading to conserved structures that recognize DNA sequences of $\sim 9$ - 18 base pairs. This technique enabled targeting of the human genome for the first time, a controversial technology [26] for constructing ZFNs that recognize a specific DNA sequence in complex genomes [32].

ZFNs were artificially constructed for strong DNA-binding affinities against single-stranded DNA viruses. Artificial zinc fingers effectively degrade a target host DNA sequence and inhibit replication of several Begomoviruses, fostering resistance in the host plant [33]. Several methods for constructing ZFNs with specific DNA-binding sites have been developed, including construction of sequence-specific ZFNs by modular assembly [34] and oligomerised pool engineering (OPEN) [35].

\section{Transcription Activator-Like Effector Nucleases (TALENs)}

TALENs emerged as a precise tool in genome engineering in 2011 due to the 
ease of designing its domain (Table 2). As molecular scissors, TALENs cause double-strand breaks followed by DNA repair pathways like NHEJ and HDR and lead to deletions, insertions, inversions or rearrangements of chromosomes. The direction of repair can be diverted toward homologous recombination by inserting a template DNA. In plants, they are combined with sequence-specific nuclease (SSN) techniques [36]. Custom-designed TALE arrays are also available commercially.

TALEs are natural proteins of plant pathogenic Xanthomonas bacteria [31]. TALE proteins contain DNA-binding domains composed of an array of 33 to 35 amino acids long repeat domains that each recognizes a single base pair at the target site. Its specificity is determined by highly variable amino acids called repeat variable di-residues (RVDs) [37].

TALEs act as an alternative to ZFNs [38]. Chimeric TALE recombinases are fusions between a hyper-activated catalytic domain from DNA invertase and a specific TALE geometry. A TALE library is used to identify variants that modify a genome with more specificity and proficiency than ZFNs. TALERs also recombine in mammalian cells. The TALER geometry provides a platform for targeted TALE domain insertion, with applications in agricultural and health biotechnology [38]. TALENs are difficult to use as compared to ZFNs due to their complicated assembly and larger repeat regions [19].

TALENs consist of a nonspecific DNA-cleavage domain and a specific DNA-binding domain (Figure 5). They are readily engineered to target specific sequences. Quick engineering of TALENs has aided research into therapeutic treatment of genetic disorders [39].

Table 2. Applications of TALENs.

\begin{tabular}{cccc}
\hline Organism & Gene(s) & Editing & Reference \\
\hline Human & hESC \& iPSC & Targeted genome engineering & {$[73]$} \\
Rat & IgM & Gene knock out & {$[74]$} \\
Zebrafish & pthA & Gene targeting & {$[75]$} \\
Zebrafish & hey2 & Gene disruption & {$[76]$} \\
Mouse & Zic2 & Site specific mutation & {$[77]$} \\
Tobacco & ALS (SurA \& SurB) & Genome engineering & {$[78]$} \\
Human & XPC locus & Targeted gene therapy & {$[79]$} \\
Soybean & FAD2-1A \& FAD2-1B & Targeted mutagenesis & {$[80]$} \\
Rat & GR ${ }^{\text {dim }}$ & Gene knock-in & {$[81]$} \\
Phaeodactylum & UDP glucose phosphorylase gene & Targeted mutagenesis & {$[82]$} \\
tricornutum & (HPFH)-175T $>$ C & Point mutation & {$[83]$} \\
Human & SP110 & Gene knock-in & {$[84]$} \\
Cattle & TRAC/dCK & TALEN mediated gene processing & {$[85]$} \\
Human & TCR \& CD52 & Multiplex genome editing & {$[86]$} \\
Human & & & \\
\hline
\end{tabular}


A

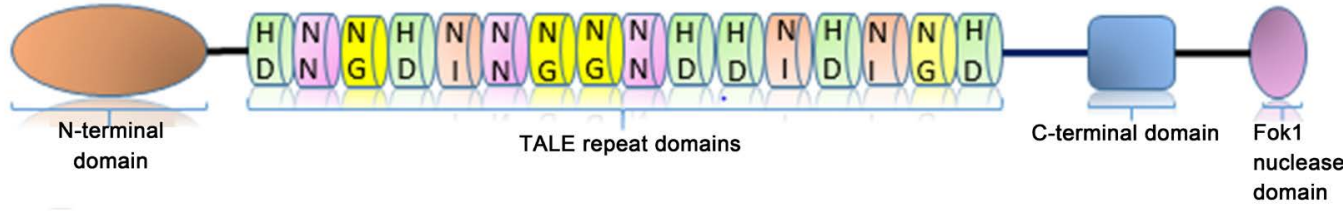

B

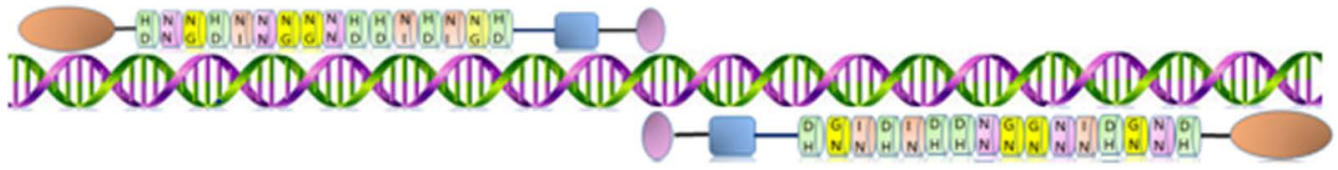

C

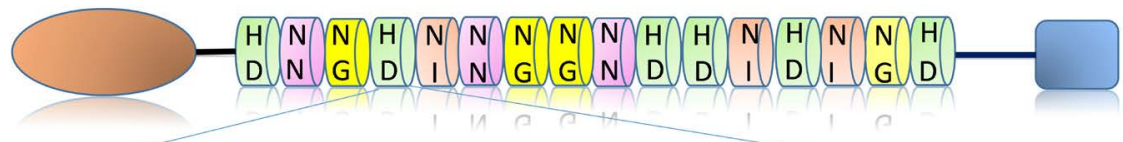

LTPDQVVAIASHDGGKQALETVQRLLPVLCQDHG

D

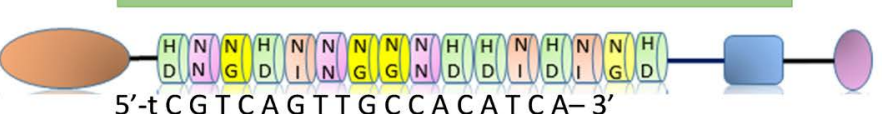

Figure 5. TALEN and TALEN arrays.

DNA methylation patterns for specific cell types aid gene expression analysis for complete genomes of diseased and normally-developing individuals. As targeted genome engineering does not remove such methylation events, their defining significance remains obscure. By fusing TALE repeats and TET1 catalytic domains, targeted demethylation of $\mathrm{CpG}$ islands can be done in humans. Fusing TALENs and TET1 hydroxylase domains enhance expression of endogenous genes in humans. These experiments indicate the significance of CpG methylation patterns for endogenous genes and their applications in research and medicine [24].

\section{CRISPR/Cas System}

The CRISPR/Cas system is an adapted immune system of prokaryotes [40]. CRISPR/Cas targets and degrades viral DNA or RNA sequences. This system works on the principal of incorporating short segments of foreign genetic material as spacers in CRISPR loci. Following transcription of the CRISPR loci, crRNA, guided RNA and Cas proteins work together to degrade foreign virus particles [40].

CRISPR is a defense system in bacteria and Archaea [41]. It consists of an array of simple sequence repeats separated by same-sized spacer regions. CRISPR arrays and their specific proteins cause resistance to viruses and plasmids through a RNA interference (RNAi) like mechanism. Acquired immunity in bacteria and archaea is achieved through CRISPR at specific loci that specifically target viruses and invading nucleic acids [42]. Genetic material of invading nucleic acids is taken up by hypervariable loci to immunize against future invasion. Mutational strategies adapted by viruses bypass the CRISPR/Cas system. CRISPR is involved in epidemiological revisions, typing resolutions, host virus 
Table 3. Applications of CRISPR/Cas system.

\begin{tabular}{|c|c|c|c|}
\hline Organism & Gene(s) & Editing & Reference \\
\hline Mouse & ASXL1 & Non sense point mutation & [87] \\
\hline Mice & Human ICC/HCC & Multiplex mutagenesis & [88] \\
\hline Human & CFTR & Homozygous deletion of F508 & [89] \\
\hline Mouse & Crygc & Correction of genetic disease & [90] \\
\hline Mice & Dystrophin gene (Dmd) & $\begin{array}{l}\text { Destrophin related duchenne } \\
\text { muscular dystrohy }\end{array}$ & [91] \\
\hline Human & Cas9 nuclease and nickase & Fanconi anemia gene correction & [92] \\
\hline Mouse & AAV9 & Postnatal genome editing & [93] \\
\hline Mouse & Fah & In vivo therapies & [94] \\
\hline Mouse & PCSK9 & Mouse hepatocyte editing & [95] \\
\hline Mammalian brain & CHD8 & Autism spectrum disorder & [96] [97] \\
\hline Wild mice & PTEN \& TP53 & Tumor suppressor genes & $\begin{array}{c}{[98][99]} \\
{[100]}\end{array}$ \\
\hline Human & HIV-I & virus & {$[101]-[107]$} \\
\hline Human & Burkitt's Lymphoma cells & Latent Herpesviridae & [108] \\
\hline Human & HPV16-E7 & Papillomavirus & [109] \\
\hline Humans & HBV cccDNA & Hepatitis-B & [110] \\
\hline Human & CXCR4 \& CCR5 & AIDS & $\begin{array}{c}{[107][108]} \\
\quad[111]\end{array}$ \\
\hline Pig & PERVs & Viral disruption & [112] \\
\hline Human & Pig Alb locus & Human Albumin production & [112] \\
\hline Corn & $\begin{array}{l}\text { LIG1, Ms26 and Ms45, } \\
\text { ALS1 and } 2\end{array}$ & $\begin{array}{l}\text { Targeted mutagenesis, Precise gene } \\
\text { editing, Site specific gene insertion }\end{array}$ & [113] \\
\hline Soybean & DD20 and DD43 & Genome editing & [111] \\
\hline Nicotiana benthamiana & ---------- & Tomato Yellow Leaf Curl Virus & [114] \\
\hline Mushrooms & --------- & CRISPR Edited Mushrooms & [115] \\
\hline
\end{tabular}

interactions, developing immunity against invading organisms and promoting viral resistance in housetrained microbes [42].

As a foreign virus or plasmid DNA invades bacteria, CRISPR-associating complex recognises invading DNA and adds unique spacer regions at the leader end of a CRISPR (Figure 6). A pre-CRISPR RNA is transcribed from the CRISPR repeat spacer array. Mature-crRNA are formed from pre-crRNA and used to guide CRISPR-associating complex to restrict analogous invading nucleic acids [42].

CRISPR/Cas machinery was used to cleave genomic DNA, resulting in modified, specific DNA sequences, either by non-homologous end joining or by homology-directed repair [6]. Three distinct stages of virus resistance through the prokaryotic CRISPR/Cas mechanism were identified [43]. First, parts of the invading DNA sequence are inserted as new spacers in the CRISPR/Cas locus. 


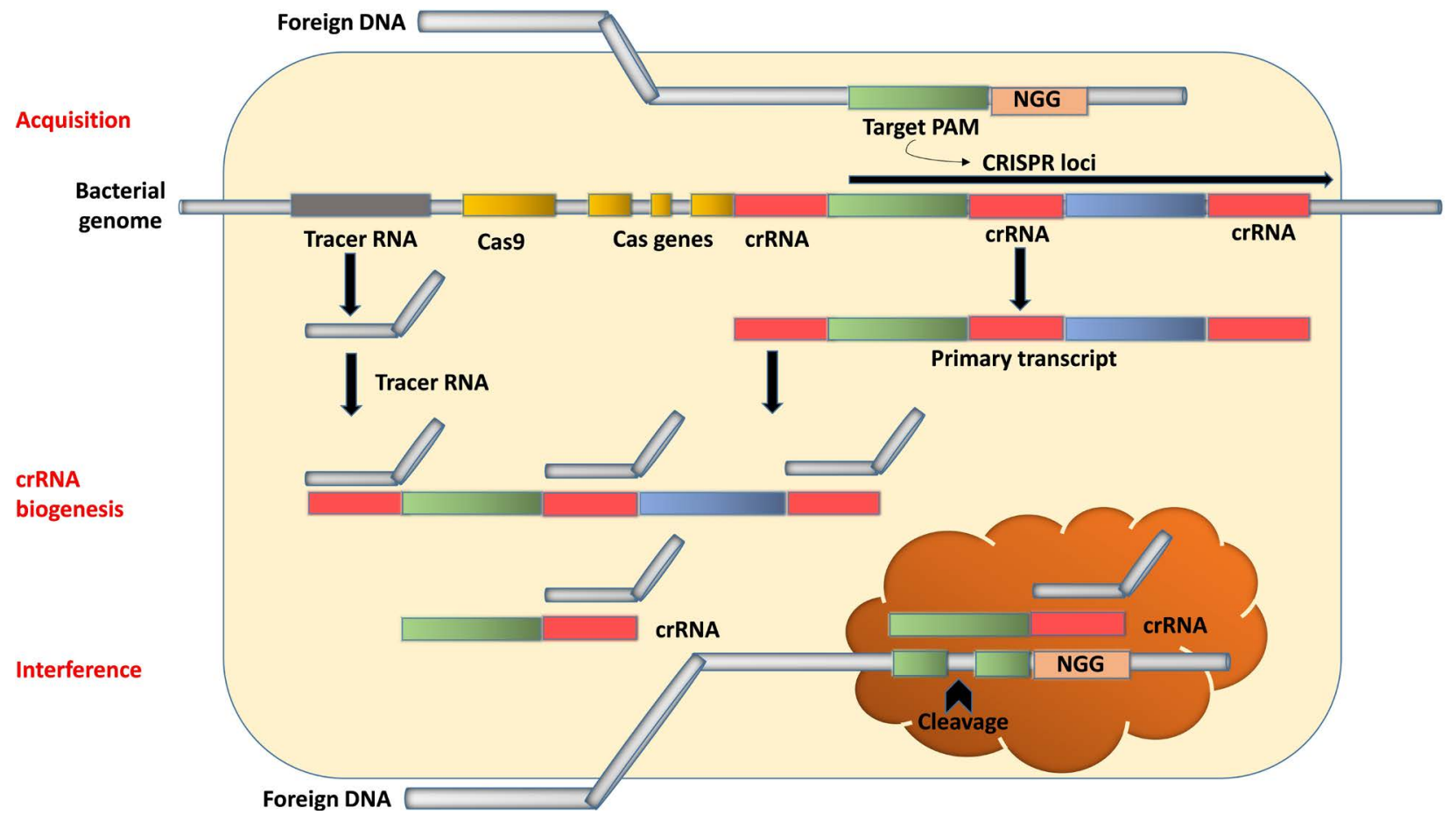

Figure 6. CRISPR/Cas mechanism in action.

Next, new spacer regions are transcribed and subsequently cleaved by Cas proteins, forming short crisper RNAs with spacer elements within them. Finally, crRNA guides Cas machinery to complimentary invading DNA or RNA, causing degradation of viruses [43].

Multiplex and homologous recombination-mediated genome engineering using CRISPR/Cas-9 and guided RNA was studied in Arabidopsis and Nicotiana banthamiana [44]. Seven target sequences in five specified genes were tested for targeted mutagenesis. Differences in mutagenesis among distinct genes may be due to different binding strength of sgRNA to individual chromatin structures and epigenetic phenomena at the targeted loci. Targeted genome editing of sgRNA and pcoCas- 9 can be studied efficiently in plant protoplasts. The foreign gene knockout rate is increased by targeting the Arabidopsis genome with multiple sgRNAs. Highly efficient, homology-directed repair in Nicotiana benthamiana was observed due to sgRNA and pcoCas-9. This technology promises accurate, marker-free genome engineering of plants [44].

The CRISPR/Cas9 system for targeted genome engineering has high competence, but several therapeutic approaches result from off-target activity of the Cas9 gene, causing safety concerns [45]. CRISPR/Cas knocks out the Tafazzin gene in pluripotent human stem cells with $54 \%$ efficiency. Whole sequencing and deep-targeted sequencing were combined to distinguish the editing effects of Cas9 on non-translating regions. HiPSC clones were modified by sequencing the complete Cas-9 genome, which didn't detect genome alterations and mutation rates. One off-target site was obtained by a single nucleotide variant (SNV) of the germline. Generation of off-target sites in the human genome by SNVs 
using an in-silico method had productivity of $1.5 \%$ to $8.5 \%$. Precise clonal ex vivo editing of genes through CRISPR/Cas9 emphasized the high value of sequencing the complete genome [45].

Targeted genome engineering of living organisms at specific sites opened diverse approaches to agricultural and medical research [46]. This technique combined with elementary molecular research has opened a vibrant field. Cell phenotype was accurately controlled by epigenetic marks and the epigenome correlated with the central dogma [47]. An actyltransferase was constructed based on CRISPR/Cas-9 composed of human acetyltransferase p300 bonded with nuclease-null dCas-9 domain. Acetylation of histone H3 lysine at position 27 was catalyzed by a fusion protein, enhancing transcription of the target gene from promoters and enhancers at both proximal and distal ends. Highly specific gene activation by targeted acetyltransferase was seen in the entire genome. Genes from enhancer regions and from individually guided RNA were better activated by the targeted acetyltranferase than by nuclease-null, dCas 9 based activators. The nuclease core of human acetyltransferase p300 was fused to programmable regions of DNA-binding proteins. Enhanced transcriptional activation lead to targeted acetylation of histone proteins and pronounced gene regulation [47].

Transgene-free genome editing in Arabidopsis, lettuce, tobacco and rice using prearranged CRISPR/Cas9 ribonucleoproteins was the next step in targeted genome engineering. RNA-guided endonuclease ribonuceoproteins (RGEN RNPs) were delivered to plant protoplasts. Two guided RNAs in Arabidopsis whose target sites were 201 base pairs from the Brassinosteroid Insensitive 1 (BRI1) gene were transformed. Transforming RNA-guided restriction endonuclease ribonucleoproteins to target Brassinosteroid Insensitive 2 (BIN2) gene in lettuce was successful. All transfected genes induced off-target mutations in homologues of corresponding genes. Targeted genome modification was achieved with RGEN RNPs and these targeted mutations were stably inherited after protoplast regeneration. About $46 \%$ targeted mutagenesis was achieved through Cas 9 and gRNA transfection in all four plant species. RNA-guided gene targeting exempts plants from GMO regulations because no recombinant DNA is present in the final plant [48].

An efficient, selection-free transformation protocol for tetraploid durum wheat and hexaploid bread wheat was developed [49]. Wheat is recalcitrant to transformation, but wheat callus cells transiently expressing DNA or RNA forms of CRISPR/Cas9 were regenerated. Highly efficient, marker-free, homozygous mutant wheat lines with undetectable transgenes were produced as a $\mathrm{T}_{\mathrm{o}}$ generation through transiently expressing CRISPR/Cas9. Selection-free transformation methods will be useful in other recalcitrant crop species [49] (Table 3).

\section{Gene Stacking: A Step Forward from Gene Editing}

Gene stacking emerged as a favorable insight for providing organisms with multiple characters. Previously, stacked products were developed by random gene 
insertions at multiple locations within organism's genome. Stacked products proved to be constructive but were producing off target effects. Pyramiding two or more genes at a precise location not only reduced the effects of off target gene activity but it provided a mechanism of removal of the whole gene cassette when the constructed stack is no longer working in future. Gene stacking strategy became more favorable by introducing molecular scissors with the addition of organism's health beneficial gene. The stacked products will be able to combat multiple diseases with additional benefit of promoting health of the organisms.

Recombinase-mediated gene stacking (RMCE) is a new transformation operation in which site-specific gene integration events can co-occur with randomly integrated transgenes (Figure 7).

Site-specific recombination systems for eukaryotic genome engineering are equally beneficial for plants and animals, but the technology is used more in plants than animals due to consumer dislike of genetically modified crops. The objective was to produce marker-free transgenic plants and to clear a genetic burden that is useless to the plant. Site-specific gene engineering also reduced ambiguous position effects. Crops are improved through addition, deletion or inversion site-specifically, without disrupting other loci [50].

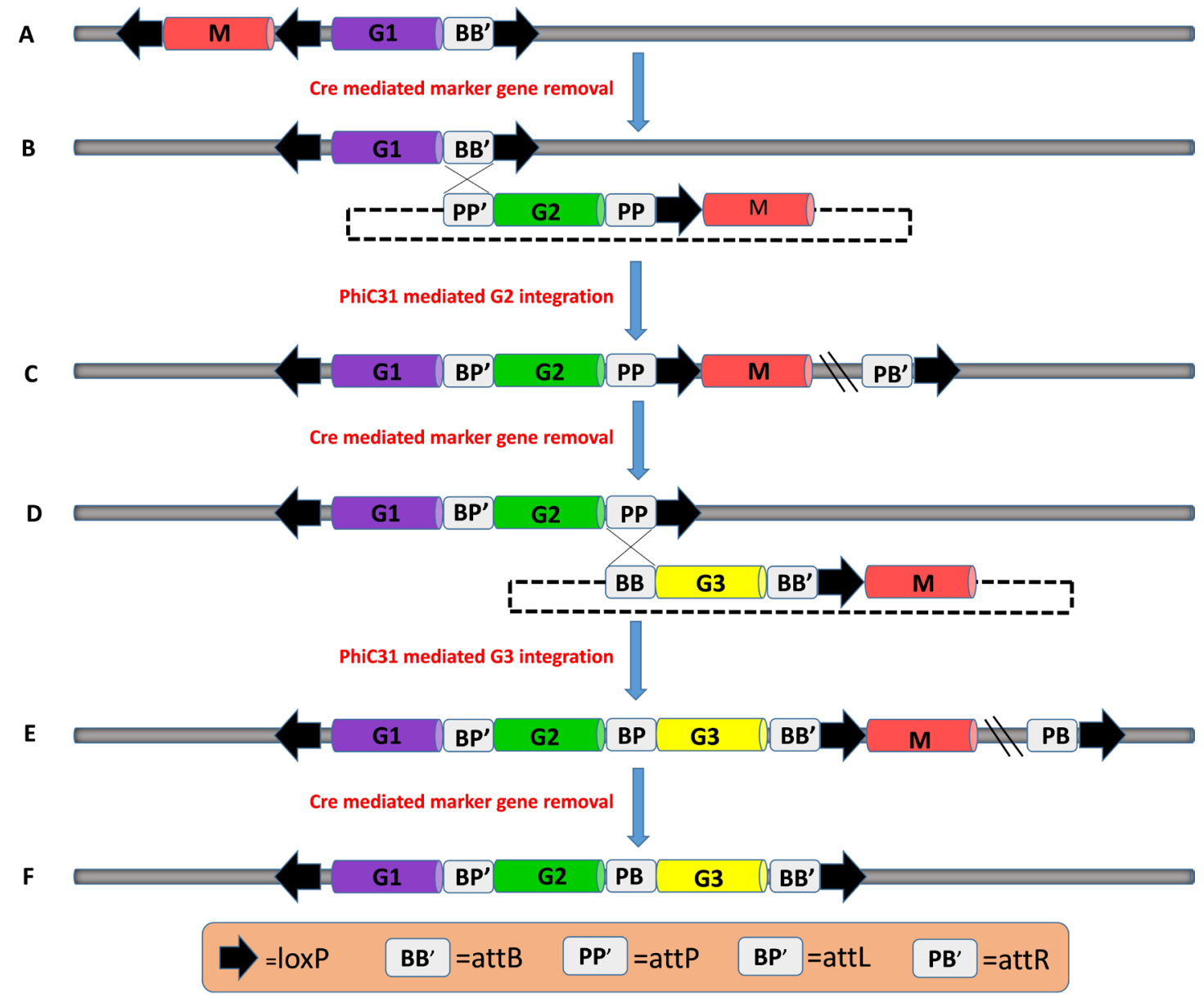

Figure 7. Gene stsacking strategy. 
Site specific gene stacking means accumulating different trait genes in a single plant and at a single locus [51]. Only a handful of commercial stacked products with pyramided traits were available in 2005 [52]. By 2010, many biotech companies had developed stacked trait products with pronounced insect and herbicide tolerance [1]. A new method for combining transgenes into a single genome used specific independent loci for recombinase-mediated deletion, insertion and inversion of transgenes [4]. Recombinase-mediated cassette exchange also helped increase gene stacking in crop plants [4].

Genome engineering uses nucleases to induce double-strand breaks at precise positions on a chromosome. A meganuclease was introduced at an endogenous specific locus contiguous to a transgenic locus of insect control region in cotton [53]. Targeted insertion of a transgene into cotton is made practical by a DNA cleavage and repair pathway. About $2 \%$ of successfully transformed embryonic calli were recovered as precise insertion events, making multi gene stacking easier by demonstrating successful single gene integration [53].

A commercial stacked maize hybrid was confirmed by transcript analysis of the transgene together with proteomic profiling [54]. The maize hybrid was more insect- and herbicide-tolerant than a single-event hybrid with same genetic background. The stacked hybrid was already genetically diverse before transformation. Protein enrichment analysis showed alteration in two major pathways: energy/carbohydrate and detoxification metabolism. A 34\% reduction in transcription of the stacked transgene was found below single-event hybrid genotypes. These scientists concluded that expression of endogenous genes is affected by stacking of two or more genes in genetically modified maize. Significant alterations in protein expression change energy/carbohydrate metabolism in stacked trait products. The new world of "omics" could provide insight on security evaluation of stacked-trait products [54].

Most commercial operations use classical breeding to introgress transgenes from a laboratory cultivar into commercial varieties suitable for different growing regions. Prior to vegetative cloning, genetic crosses were performed for varietal selection even in vegetatively propagated crops. In a diploid species, if $(1 / 4)(x)$ is the probability that " $X$ " transgenic loci will assort into a genome and " $y$ " is the number of non-transgenic loci that breeders need to accumulate in the same genome, the probability of a getting both into a breeding stack is $(1 / 4)(x+$ y). Site-specific integration of new transgenes at a preexisting locus is required to add new DNA sequences into transgenic varieties without generating a new segregating locus. Recombinase-mediated gene stacking and Bxb1 integrase from mycobacteriophage for site-specific integration between attP and attB recognition sites was used for gene stacking of tobacco [55]. A frequency of about $10 \%$ site-specific integration events was observed, with one recognition site spared for the second round of integration. Gene silencing was observed in a third site-specific integrant. About 3\% of the transformed clones showed accurate structure and reproducible expression of three consecutive gene-stacking events [55]. 


\section{Conclusion}

This review condenses the usefulness of genome editing technology to sustain health and agriculture sector of the world. Genome editing enables the clean gene technology to safely remove markers used during testing and transformations to render plants clean of any waste genetic material. This technology may eliminate the threat of plants produced with selectable markers/antibiotic resistance genes. Genome editing technology further offers a speed up process of producing genetically manipulated plants as compared to the ones produced with breeding procedures; by benefiting both the seed industry and the commercial growers. By taking into account the applications of genome editing; the types and number of available tools with advanced approaches being established offer a significant number of applications for genome editing; with high throughput single copy transgene insertions to site specific gene pyramiding, to targeted marker gene deletion. Gene stacking has now become a routine part of genome engineering projects with the purpose of developing genetically efficient plants. This may imply the growers to lessen the use of pesticides/fertilizers and produce high yielding plants to strengthen the economy. Gene stacking strategy and the general availability of genome editing tools offer additional commercial applications to industry, health and agriculture. By producing healthy food, the world's food deficit and hunger problem can be resolved. Conclusively, regulatory and public concerns to accept the use of genetically modified crops may be addressed with genome editing and clean gene technologies to foster the acceptance of genetically engineered crops worldwide.

\section{Acknowledgements}

The work is supported by Higher Education Commission of Pakistan's PhD Indigenous scholarship granted to Sabin Aslam. All suggestions, outcomes, pronouncements and inferences revealed in manuscript are of author(s) and don't reflect perspective of Higher Education Commission of Pakistan.

\section{Conflicts of Interest}

The authors declare no conflicts of interest regarding the publication of this paper.

\section{References}

[1] Que, Q., Chilton, M.D., de Fontes, C.M., He, C., Nuccio, M., Zhu, T., Wu, Y., Chen, J.S. and Shi, L. (2010) Trait Stacking in Transgenic Crops: Challenges and Opportunities. GM Crops, 4, 220-229. https://doi.org/10.4161/gmcr.1.4.13439

[2] Mette, M.F. and Houben, A. (2015) Engineering of Plant Chromosomes. Chromosome Research, 23, 69-76. https://doi.org/10.1007/s10577-014-9449-1

[3] Srivastava, V. and Ow, D.W. (2001) Single Copy Primary Transformants of Maize Obtained through the Co-Introduction of a Recombinase-Expressing Construct. Plant Molecular Biology, 46, 561-566. https://doi.org/10.1023/A:1010646100261

[4] Ow, D.W. (2011) Recombinase-Mediated Gene Stacking as a Transformation Oper- 
ating System. Journal of Integrative Plant Biology, 53, 512-519.

https://doi.org/10.1111/j.1744-7909.2011.01061.x

[5] Perez-Pinera, P., Ousterout, D.G. and Gersbach, C.A. (2012) Advances in Targeted Genome Editing. Current Opinion in Chemical Biology, 16, 268-277.

https://doi.org/10.1016/j.cbpa.2012.06.007

[6] Belhaj, K., Chaparro-Garcia, B.A., Kamoun, S. and Nekrasov, V. (2013) Plant Genome Editing Made Easy: Targeted Mutagenesis in Model and Crop Plants Using the CRISPR/Cas System. Plant Methods, 9, 39.

https://doi.org/10.1186/1746-4811-9-39

[7] Puchta, H. and Fauser, F. (2013) Gene Targeting in Plants: 25 Years Later. The International Journal of Developmental Biology, 57, 629-637.

https://doi.org/10.1387/ijdb.130194hp

[8] Sauer, B. (1987) Functional Expression of the Cre-Lox Site Specific Recombination System in the Yeast Saccharomyces cerevisiae. Molecular and Cellular Biology, 7, 2087-2096. https://doi.org/10.1128/MCB.7.6.2087

[9] Bucholtz, F. (2008) Principles of Site-Specific Recombinase (SSR) Technology. Journal of Visualized Experiments, 15, e718. https://doi.org/10.3791/718

[10] Ghosh, P., Pannunzio, N.R. and Hatfull, G.F. (2005) Synapsis in Phage Bxb1 Integration: Selection Mechanism for the Correct Pair of Recombination Sites. Journal of Molecular Biology, 349, 331-348. https://doi.org/10.1016/j.jmb.2005.03.043

[11] Pallavi, G., Pannunzio, N.R. and Hatfull, G.F. (2005) Synapsis in Phage Bxb1 Integration: Selection Mechanism for the Correct Pair of Recombination Sites. Journal of Molecular Biology, 349, 331-348. https://doi.org/10.1016/j.jmb.2005.03.043

[12] Calos, M.P. (2006) The phiC31 Integrase System for Gene Therapy. Current Gene Therapy, 6, 633-645. https://doi.org/10.2174/156652306779010642

[13] Vesna, D., Lenderts, B., Bidney, D. and Lyznik, L.A. (2008) A Cre::FLP Fusion Protein Recombines FRT or LoxP Sites in Transgenic Maize Plants. Plant Biotechnology Journal, 6, 770-781. https://doi.org/10.1111/j.1467-7652.2008.00357.x

[14] Birling, M.C., Gofflot, F. and Warot, X. (2009) Site-Specific Recombinases for Manipulation of the Mouse Genome. Methods in Molecular Biology, 561, 245-263. https://doi.org/10.1007/978-1-60327-019-9_16

[15] Allen, B.G. and Weeks, D.L. (2009) Bacteriophage C31 Integrase Mediated Transgenesis in Xenopus laevis for Protein Expression at Endogenous Levels. Methods in Molecular Biology, 518, 113-122. https://doi.org/10.1007/978-1-59745-202-1_9

[16] Fladung, M. and Becker, D. (2009) Targeted Integration and Removal of Transgenes in Hybrid Aspen (Populus tremula L. $\times$ P. tremuloides Michx.) Using Site-Specific Recombination Systems. Plant Biology, 13, 334-340. https://doi.org/10.1111/j.1438-8677.2010.00419.x

[17] Wang, Y., Yau, Y.Y., Perkins-Balding, D. and Thomsan, J.G. (2010) Recombinase Technology: Applications and Possibilities. Plant Cell Reports, 30, 267-285. https://doi.org/10.1007/s00299-010-0938-1

[18] Araki, K., Okada, Y., Araki, M. and Yamamura, K. (2010) Comparative Analysis of Right Element Mutant lox Sites on Recombination Efficiency in Embryonic Stem Cells. BMC Biotechnology, 10, 29. https://doi.org/10.1186/1472-6750-10-29

[19] Esvelt, K.M. and Wang, H.H. (2012) Genome-Scale Engineering for Systems and Synthetic Biology. Molecular Systems Biology, 9, 641. https://doi.org/10.1038/msb.2012.66

[20] Zhang, Y., Bucholtz, F., Muyrers, J.P. and Stewart, A.F. (1998) A New Logic for 
DNA Engineering Using Recombination in Escherichia coli. Nature Genetics, 2, 123-128. https://doi.org/10.1038/2417

[21] Datsenko, K.A. and Wanner, B.L. (2000) One-Step Inactivation of Chromosomal Genes in Escherichia coli. K-12 Using PCR Products. Proceedings of the National Academy of Sciences of the United States of America, 97, 6640-6645. https://doi.org/10.1073/pnas.120163297

[22] Yu, D., Ellis, H.M., Lee, E., Jenkins, N.A., Copeland, N.G. and Court, D.L. (2000) An Efficient Recombination System for Chromosome Engineering in Escherichia coli. Proceedings of the National Academy of Sciences of the United States of America, 97, 5978-5983. https://doi.org/10.1073/pnas.100127597

[23] Nandy, S., Zhao, S., Pathak, B.P., Manoharan, M. and Srivastava, V. (2015) Gene Stacking in Plant Cell Using Recombinases for Gene Integration and Nucleases for Marker Gene Deletion. BMC Biotechnology, 15, 93.

https://doi.org/10.1186/s12896-015-0212-2

[24] Maeder, M.L., Beganny, S.T., Osiak, A., Wright, D.A., Anthony, R.M., Eichtinger, M., Jianq, T., Foley, J.E., Winfrey, R.J., Townsend, J.A., Wallace, E.U., Sander, J.D., Lerch, F.M., Fu, F., Pearlberg, J., Gobel, C., Dassie, J.P., Miller, S.M.P., Porteus, M.H., Sqroi, D.C., Iafrate, A.J., Dobbs, D., Jr., P.B.M., Cathomen, T., Voytas, D.F. and Joung, J.K. (2008) Rapid "Open-Source” Engineering of Customized Zinc-Finger Nucleases for Highly Efficient Gene Modification. Molecular Cell, 31, 294-301. https://doi.org/10.1016/j.molcel.2008.06.016

[25] Ramirez, C.L., Foley, J.E., Wright, D.A., Lerch, F.M., Rahman, S.H., Cornu, T.I., Winfrey, R.J., Sander, J.D., Fu, F., Townsend, J.A., Cathomen, T., Voytas, D.F. and Joung, J.K. (2008) Unexpected Failure Rates for Modular Assembly of Engineered Zinc Fingers. Nature Methods, 5, 374-375. https://doi.org/10.1038/nmeth0508-374

[26] Kim, Y.G., Cha, J. and Chandrasegaran, S. (1996) Hybrid Restriction Enzymes: Zinc Finger Fusions to Fok I Cleavage Domain. Proceedings of the National Academy of Sciences of the United States of America, 93, 1156-1160. https://doi.org/10.1073/pnas.93.3.1156

[27] Bitnaite, J., Wah, D.A., Aggarwal, A.K. and Schildkraut, I. (1998) Fok I Dimerization Is Required for DNA Cleavage. Proceedings of the National Academy of Sciences of the United States of America, 95, 10570-10575. https://doi.org/10.1073/pnas.95.18.10570

[28] Cathomen, T. and Joung, J.K. (2008) Zinc-Finger Nucleases: The Next Generation Emerges. Molecular Therapy, 16, 1200-1207. https://doi.org/10.1038/mt.2008.114

[29] Ekker, S.C. (2008) Zinc Finger-Based Knockout Punches for Zebrafish Genes. Zebrafish, 5, 121-123. https://doi.org/10.1089/zeb.2008.9988

[30] Kim, S. and Kim, J. (2011) Targeted Genome Engineering via Zinc Finger Nucleases. Plant Biotechnology Reports, 5, 9-17. https://doi.org/10.1007/s11816-010-0161-0

[31] Gaj, T., Gersbach, C.A. and Barbas, C.F. (2013) ZFN, TALEN and CRISPR/Cas-Based Methods for Genome Engineering. Trends in Biotechnology, 31, 397-405. https://doi.org/10.1016/j.tibtech.2013.04.004

[32] Gonzalez, B., Schwimmer, L.J., Fuller, R.P., Ye, Y., Asawapornmongkol, L. and Barbas, C.F. (2010) Modular System for the Construction of Zinc Finger Libraries and Proteins. Nature Protocols, 5, 791-810. https://doi.org/10.1038/nprot.2010.34

[33] Chen, W., Qian, Y., Wu, X., Sun, Y., Wu, X. and Cheng, X. (2014) Inhibiting Replication of Begomoviruses Using Artificial Zinc Finger Nucleases That Target Viral Conserved Nucleotide Motif. Virus Genes, 48, 494-501.

https://doi.org/10.1007/s11262-014-1041-4 
[34] Beerli, R.R. and Barbas, C.F. (2002) Engineering Polydactyl Zinc-Finger Transcription Factors. Nature Biotechnology, 20, 135-141. https://doi.org/10.1038/nbt0202-135

[35] Zhang, F., Maeder, M.L., Unger-Wallace, E., Hoshaw, J.P., Royon, D., Christian, M., Li, X., Pierick, C.J., Dobbs, D., Peterson, T., Joung, J.K. and Voytas, F.D. (2010) High Frequency Targeted Mutagenesis in Arabidopsis thaliana Using Zinc Finger Nucleases. Proceedings of the National Academy of Sciences of the United States of America, 107, 12028-12033. https://doi.org/10.1073/pnas.0914991107

[36] Sprink, T., Metje, J. and Hartung, F. (2015) Plant Genome Editing by Novel Tools: TALEN and Other Sequence Specific Nucleases. Current Opinion in Biotechnology, 32, 47-53. https://doi.org/10.1016/j.copbio.2014.11.010

[37] Boch, J., Scholze, H., Schornack, S., Landqarf, A., Hahn, S., Kay, S., Lahaye, T., Nickstadt, A. and Bonas, U. (2009) Breaking the Code of DNA Binding Specificity of TAL-Type III Effectors. Science, 326, 1509-1512. https://doi.org/10.1126/science.1178811

[38] Mercer, A.C., Gaj, T., Fuller, R.P. and Barbas, C.F. (2012) Chimeric TALE Recombinases with Programmable DNA Sequence Specificity. Nucleic Acids Research, 40, 11163-11172. https://doi.org/10.1093/nar/gks875

[39] Joung, J.K. and Sander, J.D. (2013) TALENs: A Widely Applicable Technology for Targeted Genome Editing. Molecular and Cellular Biology, 14, 49-55. https://doi.org/10.1038/nrm3486

[40] Van der Oost, J., Westra, E.R., Jackson, R.N. and Wiedenheft, B. (2014) Unravelling the Structural and Mechanistic Basis of CRISPR-Cas Systems. Nature Reviews Microbiology, 12, 479-492. https://doi.org/10.1038/nrmicro3279

[41] Sorek, R., Kunin, V. and Huqenholtz, P. (2008) CRISPR-A Widespread System That Provides Acquired Resistance against Phages in Bacteria and Archaea. Nature Reviews Microbiology, 6, 181-186. https://doi.org/10.1038/nrmicro1793

[42] Horvath, P. and Barrangou, R. (2010) CRISPR/Cas, the Immune System of Bacteria and Archaea. Science, 327, 167-170. https://doi.org/10.1126/science.1179555

[43] Jore, M.M., Lundgran, M., Duijn, E., Bultema, J.B., Westra, E.R., Waghmare, S.P., Wiedenheft, B., Pul, U., Wurm, R., Wagner, R., Beijer, M.R., Barendregt, A., Zhou, K., Snijders, A.P.L., Dickman, M.J., Doudna, J.A., Boekema, E.J., Heck, A.J.R., Van der Oost, J. and Bronus, S.J.J. (2011) Structural Basis for CRISPR RNA-Guided DNA Recognition by Cascade. Nature Structural \& Molecular Biology, 18, 529-536. https://doi.org/10.1038/nsmb.2019

[44] Li, J., Zhang, D. and Sheen, J. (2014) Cas9-Based Genome Editing in Arabidopsis and Tobacco. Methods in Enzymology, 546, 459-472. https://doi.org/10.1016/B978-0-12-801185-0.00022-2

[45] Yang, L., Grishin, D., Wang, G., Aach, J., Zhang, C.Z., Chari, R., Homsy, J., Cai, X., Zhao, Y., Fan, J.B., Seidman, C., Seidman, J., Pu, W. and Church, G. (2014) Targeted and Genome-Wide Sequencing Reveal Single Nucleotide Variations Impacting Specificity of Cas9 in Human Stem Cells. Nature Communications, 5, Article No. 5507. https://doi.org/10.1038/ncomms6507

[46] Rajendran, S.R., Yau, Y.Y., Pandey, D. and Kuar, A. (2015) CRISPR-Cas9 Based Genome Engineering: Opportunities in Agri-Food-Nutrition and Healthcare. OMICS, 19, 261-275. https://doi.org/10.1089/omi.2015.0023

[47] Hilton, I.B., D’Ippolito, A.M., Vockley, C.M., Thakore, P.I., Crawford, G.E., Reddy, T.E. and Gersbach, C.A. (2015) Epigenome Editing by a CRISPR-Cas9-Based Acetyltransferase Activates Genes from Promoters and Enhancers. Nature Biotechnol- 
ogy, 30, 510-517. https://doi.org/10.1038/nbt.3199

[48] Woo J.W., Kim, J., Kwon, S.I., Corvalan, C., Cho, S.W., Kim, H., Kim, S.G., Kim, S.T., Choe, S. and Kim, J.S. (2015) DNA-Free Genome Editing in Plants with Preassembled CRISPR-Cas9 Ribonucleoproteins. Nature Biotechnology, 33, 1162-1164. https://doi.org/10.1038/nbt.3389

[49] Zhang, Y., Liang, Z., Zong, Y., Wang, Y., Liu, J., Chen, K., Qiu, J. and Gao, C. (2016) Efficient and Transgene-Free Genome Editing in Wheat through Transient Expression of CRISPR/Cas9 DNA or RNA. Nature Communications, 7, Article No. 12617. https://doi.org/10.1038/ncomms12617

[50] Ow, D.W. (2016) The Long Road to Recombinase-Mediated Plant Transformation. Plant Biotechnology Journal, 14, 441-447. https://doi.org/10.1111/pbi.12472

[51] Taverniers, I., Papazova, N., Bertheau, Y., Loose, M.D. and Jensen, A.H. (2008) Gene Stacking in Transgenic Plants: Towards Compliance between Definitions, Terminology, and Detection within the EU Regulatory Framework. Environmental Biosafety Research, 7, 197-218. https://doi.org/10.1051/ebr:2008018

[52] Halpin, C. (2005) Gene Stacking in Transgenic Plants-The Challenge for 21st Century Plant Biotechnology. Plant Biotechnology Journal, 3, 141-155. https://doi.org/10.1111/j.1467-7652.2004.00113.x

[53] D’Halluin, K., Vanderstraeten, C., Van-Hulle, J., Rosolowska, J., Van-De-Brande, I., Pennewaert, A., D’Hont, K., Bossut, M., Jantz, D., Ruiter, R. and Broadhvest, J. (2013) Targeted Molecular Trait Stacking in Cotton through Targeted Double-Strand Break Induction. Plant Biotechnology Journal, 11, 933-941. https://doi.org/10.1111/pbi.12085

[54] Agapito-Tenfen, S.Z., Vilperte, V., Benevenuto, R.F., Rover, C.M., Traavik, T.I. and Nodari, R.O. (2014) Effect of Stacking Insecticidal Cry and Herbicide Tolerance Epsps Transgenes on Transgenic Maize Proteome. BMC Plant Biology, 4, 346-348. https://doi.org/10.1186/s12870-014-0346-8

[55] Hou, L., Yau, Y., Wei, J., Han, Z., Dong, Z. and Ow, D.W. (2014) An Open-Source System for in Planta Gene Stacking by Bxb1 and Cre Recombinases. Molecular Plant, 7, 1756-1765. https://doi.org/10.1093/mp/ssu107

[56] Carroll, D. (2008) Zinc-Finger Nucleases as Gene Therapy Agents. Gene Therapy, 15, 1463-1468. https://doi.org/10.1038/gt.2008.145

[57] Shukla, V.K., Doyon, Y. and Miller, J.C. (2009) Precise Genome Modification in the Crop Species Zea mays Using Zinc-Finger Nucleases. Nature, 459, 437-441. https://doi.org/10.1038/nature07992

[58] Cai C.Q., Doyon, Y., Miller, W.M., Dekelver, J.C., Moehle, R.C., Rock, E.A., Lee, J.M., Garrison, Y.L., Schulenberg, R., Blue, L., Worden, R., Baker, A., Faraji, L., Zhang, F., Holmes, L., Rebar, M.C., Collingwood, E.J., Rubin-Wilson, T.N., Gregory, B., Urnov, P.D. and Petolino, F.D. (2008) Targeted Transgene Integration in Plant Cells Using Designed Zinc Finger Nucleases. Plant Molecular Biology, 69, 699-709. https://doi.org/10.1007/s11103-008-9449-7

[59] Townsend, J.A., Wright, D.A., Winfrey, R.J., Fu, F., Maeder, M.L., Joung, J.K. and Voytas, D.F. (2009) High-Frequency Modification of Plant Genes Using Engineered Zinc-Finger Nucleases. Nature, 459, 442-445. https://doi.org/10.1038/nature07845

[60] Geurts, A.M., Cost, G.J., Freyvert, Y., Zeitler, B., Miller, J.C., Choi, V.M., Jenkins, S.S., Wood, A., Cui, X., Meng, X., Vincent, A., Lam, S., Michalkiewicz, M., Schilling, R., Foeckler, J., Kalloway, S., Weiler, H., Menoret, S., Anegon, I., Davis, G.D., Zhang, L., Rebar, E.J., Gregory, P.D., Urnov, F.D., Jacob, H.J. and Buelow, R. (2009) 
Knockout Rats via Embryo Microinjection of Zinc-Finger Nucleases. Science, 325, 433-433. https://doi.org/10.1126/science.1172447

[61] Ochiai, H., Fujita, K., Suzuki, K.I., Nishikawa, M., Shibata, T., Sakamoto, N. and Yamamoto, T. (2010) Targeted Mutagenesis in the Sea Urchin Embryo Using Zinc-Finger Nucleases. Genes Cells, 15, 875-885. https://doi.org/10.1111/j.1365-2443.2010.01425.x

[62] Takasu, Y., Kobayashi, I., Beumer, K., Uchino, K., Sezutsu, H., Sajwan, S., Carroll, D., Tamura, T. and Zurovec, M. (2010) Targeted Mutagenesis in the Silkworm Bombyx mori Using Zinc Finger Nuclease mRNA Injection. Insect Biochemistry and Molecular Biology, 40, 759-765. https://doi.org/10.1016/j.ibmb.2010.07.012

[63] Osakabe, K., Osakabe, Y. and Toki, S. (2010) Site-Directed Mutagenesis in Arabidopsis Using Custom-Designed Zinc Finger Nucleases. Proceedings of the National Academy of Sciences of the United States of America, 107, 12034-12039. https://doi.org/10.1073/pnas.1000234107

[64] Goldberg, A.D., Banaszynski, L.A., Noh, K.M., Lewis, P.W., Elsaesser, S.J., Stadler, S., Dewell, S., Law, M., Guo, X., Li, X., Wen, D., Chapgier, A., Dekelver, R.C., Miller, J.C., Lee, Y.L., Boydston, E.A., Holmes, M.C., Gregory, P.D., Greally, J.M., Rafii, S., Yang, C., Scambler, P.J., Garrick, D., Gibbons, R.J., Higgs, D.R., Cristea, I.M., Urnov, F.D., Zheng, D. and Allis, C.D. (2010) Distinct Factors Control Histone Variant H3.3 Localization at Specific Genomic Regions. Cell, 140, 678-691. https://doi.org/10.1016/j.cell.2010.01.003

[65] Curtin, S.J., Zhang, F., Sander, J.D., Haun, W.J., Starker, C., Baltes, N.J., Reyon, D., Dahlborg, E.J., Goodwin, M.J., Coffman, A.P., Dobbs, D., Joung, J.K., Voytas, D.F. and Stupar, R.M. (2011) Targeted Mutagenesis of Duplicated Genes in Soybean with Zinc-Finger Nucleases. Plant Physiology, 156, 466-473. https://doi.org/10.1104/pp.111.172981

[66] Young J.J., Cherone, J.M., Doyon, Y., Ankoudinova, I., Faraji, F.M., Lee, A.H., Ngo, C., Guschin, D.Y., Paschon, D.E., Miller, J.C., Zhang, L., Rebar, E.J., Gregory, P.D., Urnov, F.D., Harland, R.M. and Zeitler, B. (2011) Efficient Targeted Gene Disruption in the Somatic and Germ Line of the Frog (Xenopus tropicalis) Using Engineered Zinc-Finger Nucleases. Proceedings of the National Academy of Sciences of the United States of America, 108, 7052-7057.

https://doi.org/10.1073/pnas.1102030108

[67] Flisikowska, T., Thorey, I.S., Offner, S., Ros, F., Lifke, V., Zeitler, B., Rottmann, O., Vincent, A., Zhang, L., Jenkins, S., Niersbach, H., Kind, A.J., Gregory, P.D., Schnieke, A.E. and Platzer, J. (2011) Efficient Immunoglobulin Gene Disruption and Targeted Replacement in Rabbit Using Zinc Finger Nucleases. PLoS ONE, 6, e21045. https://doi.org/10.1371/journal.pone.0021045

[68] Hauschild, J., Petersen, B., Santiago, Y., Queisser, A.L., Carnwath, J.W., Lucas-Hahn, A., Zhang, L., Meng, X., Gregory, P.D., Schwinzer, R., Cost, G.J. and Niemann, H. (2011) Efficient Generation of a Biallelic Knockout in Pigs Using Zinc-Finger Nucleases. Proceedings of the National Academy of Sciences of the United States of America, 108, 12013-12017. https://doi.org/10.1073/pnas.1106422108

[69] Li, H., Haurigot, V., Doyon, Y., Li, T., Wong, S.Y., Bhagwat, A.S., Malani, N., Anguela, X.M., Sharma, R., Ivanciu, L., Murphy, S.L., Finn, J.D., Khazi, F.R., Zhou, S., Paschon, D.E., Rebar, E.J., Bushman, F.D., Gregory, P.D., Holmes, M.C. and High, K.A. (2011) In Vivo Genome Editing Restores Haemostasis in a Mouse Model of Haemophilia. Nature, 475, 217-221. https://doi.org/10.1038/nature10177

[70] Yu, S., Luo, J., Song, Z., Ding, F., Dai, Y. and Li, N. (2011) Highly Efficient Modifi- 
cation of Beta-Lactoglobulin (BLG) Gene via Zinc-Finger Nucleases in Cattle. Cell Research, 21, 1638-1640. https://doi.org/10.1038/cr.2011.153

[71] Wood, A.J., Lo, T.W., Zeitler, B., Pickle, C.S., Ralston, E.J., Lee, A.H., Amora, R., Miller, J.C., Leung, E., Meng, X., Zhang, L., Rebar, E.J., Gregory, P.D., Urnov, F.D. and Meyer, B.J. (2011) Targeted Genome Editing across Species Using ZFNs and TALENs. Science, 333, 307. https://doi.org/10.1126/science.1207773

[72] Tebas P., Stein, D., Frank, T.L., Wang, S.Q., Lee, G., Spratt, S.K., Surosky, R.T., Giedlin, M.A., Nichol, G., Holmes, M.C., Gregory, D.P., Ando, D.G., Kalos, M., Collman, R.G., Binder-Scholl, G., Plesa, G., Hwang, W., Bruce, L.L. and Carl, J.H. (2014) Gene Editing of CCR5 in Autologous CD4 T Cells of Persons Infected with HIV. The New England Journal of Medicine, 370, 901-910. https://doi.org/10.1056/NEJMoa1300662

[73] Hockemeyer, D., Wang, H., Kiani, S., Lai, C.S., Gao, Q., Cassady, J.P., Cost, G.J., Zhang, L., Santiago, Y., Miller, J.C., Zeitler, B., Cherone, J.M., Meng, X., Hinkley, S.J., Rebar, E.J., Gregory, P.D., Urnov, F.D. and Jaenisch, R. (2011) Genetic Engineering of Human Pluripotent Cells Using TALE Nucleases. Nature Biotechnology, 29, 731-734. https://doi.org/10.1038/nbt.1927

[74] Tesson, L., Usal, C., Ménoret, S.V., Leung, E., Niles, B.J., Remy, S.V., Santiago, Y., Vincent, A., Meng, X., Zhang, L., Gregory, P.D., Anegon, I. and Cost, G.J. (2011) Knockout Rats Generated by Embryo Microinjection of TALENs. Nature Biotechnology, 29, 695-696. https://doi.org/10.1038/nbt.1940

[75] Huang, P., Xiao, A., Zhou, M., Zhu, Z., Lin, S. and Zhang, B. (2011) Heritable Gene Targeting in Zebrafish Using Customized TALENs. Nature Biotechnology, 29, 699-700. https://doi.org/10.1038/nbt.1939

[76] Sander, J.D., Cade, L., Khayter, C., Reyon, D., Peterson, R.T., Joung, J.K. and Yeh, J.J. (2011) Targeted Gene Disruption in Somatic Zebrafish Cells Using Engineered TALENs. Nature Biotechnology, 29, 697-698. https://doi.org/10.1038/nbt.1934

[77] Davies, B., Davies, G., Preece, C., Puliyadi, R., Szumska, D. and Bhattacharya, S. (2013) Site Specific Mutation of the Zic2 Locus by Microinjection of TALEN mRNA in Mouse CD1, C3H and C57BL/6J Oocytes. PLoS ONE, 8, 60216. https://doi.org/10.1371/journal.pone.0060216

[78] Zhang, Y., Zhang, F., Li, X., Baller, J.A., Qi, Y., Starker, C.G., Bogdanove, A.J. and Voytas, D.F. (2013) Transcription Activator-Like Effector Nucleases Enable Efficient Plant Genome Engineering. Plant Physiology, 161, 20-27. https://doi.org/10.1104/pp.112.205179

[79] Dupuy, A., Valton, J., Leduc, S., Armier, J., Galetto, R., Gouble, A., Lebuhotel, C., Stary, A., Paques, F., Duchateau, P., Sarasin, A. and Daboussi, F. (2013) Targeted Gene Therapy of Xeroderma pigmentosum Cells Using Meganuclease and TALEN $^{\mathrm{mm}}$. PLOS ONE, 8, e78678. https://doi.org/10.1371/journal.pone.0078678

[80] Haun, W., Coffman, A., Clasen, B.M., Demorest, Z.L., Lowy, A., Ray, E., Retterath, A., Stoddard, T., Juillerat, A., Cedrone, F., Mathis, L., Voytas, D.F. and Zhang, F. (2014) Improved Soybean Oil Quality by Targeted Mutagenesis of the Fatty Acid Desaturase 2 Gene Family. Plant Biotechnology Journal, 12, 934-940. https://doi.org/10.1111/pbi.12201

[81] Ponce de Leon, V., Merrialt, A., Tesson, L., Anegon, I. and Hummler, E. (2014) Generation of TALE-Mediated GR ${ }^{\text {dim }}$ Knock-In Rats by Homologous Recombination. PLoS ONE, 9, e88146. https://doi.org/10.1371/journal.pone.0088146

[82] Daboussi, F., Leduc, S., Maréchal, A., Dubois, G., Guyot, V., Perez-Michaut, C., Amato, A., Falciatore, A., Juillerat, A., Beurdeley, M., Voytas, D.F., Cavarec, L. and Duchateau, P. (2014) Genome Engineering Empowers the Diatom Phaeodactylum 
tricornutum for Biotechnology. Nature Communications, 5, Article No. 3831. https://doi.org/10.1038/ncomms4831

[83] Wienert, B., Funnell, A.P.W., Norton, L.J., Pearson, R.C.M., Wilkinson-White, L.E., Lester, K., Vadolas, J., Porteus, M.H., Matthews, J.M., Quinlan, K.G.R. and Crossley, M. (2015) Editing the Genome to Introduce a Beneficial Naturally Occurring Mutation Associated with Increased Fetal Globin. Nature Communications, 6, Article No. 7085. https://doi.org/10.1038/ncomms8085

[84] Wu, H., Wang, Y., Zhang, Y., Yang, M., Lv, J., Liu, J. and Zhang, Y. (2015) TALE Nickase-Mediated SP110 Knocking Endows Cattle with Increased Resistance to Tuberculosis. Proceedings of the National Academy of Sciences of the United States of America, 112, 1530-1539. https://doi.org/10.1073/pnas.1421587112

[85] Valton, J., Guyot, V., Marechal, A., Filhol, J.M., Juillerat, A., Duclert, A., Duchateau, P. and Poirot, L. (2015) A Multidrug-Resistant Engineered CAR T Cell for Allogeneic Combination Immunotherapy. Molecular Therapy, 23, 1507-1518. https://doi.org/10.1038/mt.2015.104

[86] Poirot, L., Philip, B., Schiffer-Mannioui, C., Diane, C.L., Chion-Sotinel, I., Derniame, S., Bas, C., Potrel, P. and Lemaire, L. (2015) Multiplex Genome Edited T-Cell Manufacturing Platform for "Off-the-Shelf” Adoptive T-Cell Immunotherapies. Cancer Research, 75, 3321. https://doi.org/10.1158/0008-5472.CAN-14-3321

[87] Valletta, S., Dolatshad, H., Bartenstein, M., Yip, B.H., Bello, E., Gordon, S., Yu, Y., Shaw, J., Roy, S., Scifo, L., Schuh, A., Pellagatti, A., Fulga, T.A., Verma, A. and Boultwood, J. (2015) ASXL1 Mutation Correction by CRISPR/Cas9 Restores Gene Function in Leukemia Cells and Increases Survival in Mouse Xenografts. Oncotarget, 6, 44061-4407. https://doi.org/10.18632/oncotarget.6392

[88] Weber, J., Ollinger, R., Friedrich, M., Ehmer, U., Barenboim, M., Steiger, K., Heid, I., Mueller, S., Maresch, R., Engleitner, T., Gross, N., Geumann, U., Fu, B., Segler, A., Yuan, D., Lange, S., Strong, A., de la Rosa, J., Esposito, I., Liu, P., Cadinanos, J., Vassiliou, G.S., Schmid, R.M., Schneider, G., Unger, K., Yang, F., Braren, R., Heikenwalder, M., Varela, I., Saur, D., Bradley, A. and Rad, R. (2015) CRISPR/Cas9 Somatic Multiplex-Mutagenesis for High-Throughput Functional Cancer Genomics in Mice. Proceedings of the National Academy of Sciences of the United States of America USA, 112, 13982-13987. https://doi.org/10.1073/pnas.1512392112

[89] Firth, A.L., Menon, T., Parker, G.S., Qullas, S.J., Lewis, B.M., Ke, E., Dargitz, C.T., Wright, R., Khanna, A., Gage, F.H. and Verma, I.M. (2015) Functional Gene Correction for Cystic Fibrosis in Lung Epithelial Cells Generated from Patient iPSCs. Cell Reports, 12, 1385-1390. https://doi.org/10.1016/j.celrep.2015.07.062

[90] Wu, Y., Liang, D., Wang, Y., Bai, M., Tang, W., Bao, S., Yan, Z., Li, D. and Li, J. (2013) Correction of a Genetic Disease in Mouse via Use of CRISPR-Cas9. Cell Stem Cell, 13, 659-662. https://doi.org/10.1016/j.stem.2013.10.016

[91] Long, C., McAnally, J.R., Shelton, J.M., Mireault, A.A., Bassel-Duby, R. and Olson, E.N. (2014) Prevention of Muscular Dystrophy in Mice by CRISPR/Cas9-Mediated Editing of Germline DNA. Science, 345, 1184-1188. https://doi.org/10.1126/science.1254445

[92] Osborn, M.J., Gabriel, R., Webber, B.R., DeFeo, A.P., McElory, A.N., Jarjour, J., Starker, C.G., Wagner, J.E., Joung, J.K., Voytas, D.F., Von, C.K., Schmidt, M., Blazar, B.R. and Tolar, J. (2015) Fanconi Anemia Gene Editing by the CRISPR/Cas9 System. Human Gene Therapy, 26, 114-126. https://doi.org/10.1089/hum.2014.111

[93] Long, C., Amoasii, L., Mireault, A.A., McAnally, J.R., Li, H., Sanchez-Ortiz, E., Bhattacharyya, S., Shelton, J.M., Bassel-Duby, R. and Olson, E.N. (2016) Postnatal Genome Editing Partially Restores Dystrophin Expression in a Mouse Model of 
Muscular Dystrophy. Science, 351, 400-403. https://doi.org/10.1126/science.aad5725

[94] Yin, H., Xue, W., Chen, S., Bogorad, R.L., Benedetti, E., Grompe, M., Koteliansky, V., Sharp, P.A., Jacks, T. and Anderson, D.G. (2014) Genome Editing with Cas9 in Adult Mice Corrects a Disease Mutation and Phenotype. Nature Biotechnology, 32, 551-553. https://doi.org/10.1038/nbt.2884

[95] Ding, Q., Strong, A., Patel, K.M., Ng, S.L., Gosis, B.S., Regan, S.N., Cowan, C.A., Rader, D.J. and Musunuru, K. (2014) Permanent Alteration of PCSK9 with in Vivo CRISPR-Cas9 Genome Editing. Circulation Research, 115, 488-492. https://doi.org/10.1161/CIRCRESAHA.115.304351

[96] Heidenreich, M. and Zhang, F. (2016) Applications of CRISPR-Cas Systems in Neuroscience. Nature Reviews Neuroscience, 17, 36-44. https://doi.org/10.1038/nrn.2015.2

[97] Swiech, L., Heidenreich, M., Banerjee, A., Habib, N., Li, Y., Trombetta, J., Sur, M. and Zhang, F. (2015) In Vivo Interrogation of Gene Function in the Mammalian Brain Using CRISPR-Cas9. Nature Biotechnology, 33, 102-106. https://doi.org/10.1038/nbt.3055

[98] Yao, S., He, Z. and Chen, C. (2015) CRISPR/Cas9-Mediated Genome Editing of Epigenetic Factors for Cancer Therapy. Human Gene Therapy, 26, 463-471. https://doi.org/10.1089/hum.2015.067

[99] Xue, W., Chen, S., Yin, H., Tammela, T., Papagiannakopoulos, T., Joshi, N.S., Cai, W., Yang, G., Bronson, R., Crowley, D.G., Zhang, F., Anderson, D.G., Sharp, P.A. and Jacks, T. (2014) CRISPR-Mediated Direct Mutation of Cancer Genes in the Mouse Liver. Nature, 514, 380-384. https://doi.org/10.1038/nature13589

[100] Wang, D., Mou, H., Li, S., Li, Y., Hough, S., Tran, K., Li, J., Yin, H., Anderson, D.G., Sontheimer, E.J., Weng, Z., Gao, G. and Xue, W. (2015) Adenovirus-Mediated Somatic Genome Editing of Pten by CRISPR/Cas9 in Mouse Liver in Spite of Cas9-Specific Immune Responses. Human Gene Therapy, 26, 432-442. https://doi.org/10.1089/hum.2015.087

[101] Hu, W., Kaminski, R., Yang, F., Zhang, Y., Cosentino, L., Li, F., Luo, B., Alvarez-Carbonell, D., Garcia-Mesa, Y., Karn, J., Mo, X. and Khalili, K. (2014) RNA-Directed Gene Editing Specifically Eradicates Latent and Prevents New HIV-1 Infection. Proceedings of the National Academy of Sciences of the United States of America USA, 111, 11461-11466. https://doi.org/10.1073/pnas.1405186111

[102] Li, Z., Liu, Z.B., Xing, A., Moon, B.P., Koelhoffer, J.P., Huang, L., Ward, R.T., Clifton, E., Falco, S.C. and Cigan, A.M. (2015) Cas9-Guide RNA Directed Genome Editing in Soybean. Plant Physiology, 169, 960-970. https://doi.org/10.1104/pp.15.00783

[103] Wang, W., Ye, C., Liu, J., Zhang, D., Kimata, J.T. and Zhou, P. (2014) CCR5 Gene Disruption via Lentiviral Vectors Expressing Cas9 and Single Guided RNA Renders Cells Resistant to HIV-1 Infection. PLoS ONE, 9, e115987. https://doi.org/10.1371/journal.pone.0115987

[104] Ye, L., Wang, J., Beyer, A.L., Teque, F., Cradick, T.J., Qi, Z., Chang, J.C., Bao, G., Muench, M.O., Yu, J., Levy, J.A. and Kan, Y.W. (2014) Seamless Modification of Wild-Type Induced Pluripotent Stem Cells to the Natural CCR5 $\Delta 32$ Mutation Confers Resistance to HIV Infection. Proceedings of the National Academy of Sciences of the United States of America USA, 111, 9591-9596. https://doi.org/10.1073/pnas.1407473111

[105] Zhang, S. and Sodroski, J. (2015) Efficient Human Immunodeficiency Virus (HIV-1) Infection of Cells Lacking PDZD8. Virology, 481, 73-78. 
https://doi.org/10.1016/j.virol.2015.01.034

[106] Liao, H.K., Gu, Y., Diaz, A., Marlett, J., Takahashi, Y., Li, M., Suzuki, K., Xu, R., Hishida, T., Chang, C.J., Esteban, C.R., Young, J. and Izpisua-Belmonte, J.C. (2015) Use of the CRISPR/Cas9 System as an Intracellular Defense against HIV-1 Infection in Human Cells. Nature Communications, 6, Article ID: 6413. https://doi.org/10.1038/ncomms7413

[107] Hou, P., Chen, S., Wang, S., Yu, X., Chen, Y., Jiang, M., Zhuang, K., Ho, W., Hou, W., Huang, J. and Guo, D. (2015) Genome Editing of CXCR4 by CRISPR/cas9 Confers Cells Resistant to HIV-1 Infection. Scientific Reports, 5, Article No. 15577. https://doi.org/10.1038/srep15577

[108] Wang, J. and Quake, S.R. (2014) RNA-Guided Endonuclease Provides a Therapeutic Strategy to Cure Latent Herpesviridae Infection. Proceedings of the National Academy of Sciences of the United States of America USA, 111, 13157-13162. https://doi.org/10.1073/pnas.1410785111

[109] Hu, Z., Yu, L., Zhu, D., Ding, W., Wang, X., Zhang, C., Wang, L., Jiang, X., Shen, H., He, D., Li, K., Xi, L., Ma, D. and Wang, H. (2014) Disruption of HPV16-E7 by CRISPR/Cas System Induces Apoptosis and Growth Inhibition in HPV16 Positive Human Cervical Cancer Cells. BioMed Research International, 2014, Article ID: 612823. https://doi.org/10.1155/2014/612823

[110] Kennedy, E.M., Bassit, L.C., Mueller, H., Kornepati, A.V.R., Bogerd, H.P., Nie, T., Chatterjee, P., Javanbakht, H., Schinazi, R.F. and Cullen, B.R. (2015) Suppression of Hepatitis B Virus DNA Accumulation in Chronically Infected Cells Using a Bacterial CRISPR/Cas RNA-Guided DNA Endonuclease. Virology, 476, 196-205. https://doi.org/10.1016/j.virol.2014.12.001

[111] Li, C., Guan, X., Du, T., Jin, W., Wu, B., Liu, Y., Wang, P., Hu, B., Griffin, G.E., Shattock, R.J. and Hu, Q. (2015) Inhibition of HIV-1 Infection of Primary CD4+ T-Cells by Gene Editing of CCR5 Using Adenovirus-Delivered CRISPR/Cas9. Journal of General Virology, 96, 2381-2393. https://doi.org/10.1099/vir.0.000139

[112] Peng, J., Wang, Y., Jiang, J., Zhou, X., Song, L., Wang, L., Ding, C., Qin, J., Liu, L., Wang, W., Liu, J., Huang, X., Wei, H. and Zhang, P. (2015) Production of Human Albumin in Pigs through CRISPR/Cas9-Mediated Knockin of Human cDNA into Swine Albumin Locus in the Zygotes. Scientific Reports, 5, Article No. 16705. https://doi.org/10.1038/srep16705

[113] Svitashev, S., Young, J.K., Schwartz, C., Gao, H., Falco, S.C. and Cigan, A.M. (2015) Targeted Mutagenesis, Precise Gene Editing, and Site-Specific Gene Insertion in Maize Using Cas9 and Guide RNA. Plant Physiology, 169, 931-945. https://doi.org/10.1104/pp.15.00793

[114] Ali, A., Bang, S.W., Chung, S.M. and Staub, J.E. (2015) Plant Transformation via Pollen Tube-Mediated Gene Transfer. Plant Molecular Biology Reporter, 33, 742-747. https://doi.org/10.1007/s11105-014-0839-5

[115] Waltz, E. (2016) Gene-Edited CRISPR Mushroom Escapes US Regulation. Nature, 532, 293. https://doi.org/10.1038/nature.2016.19754 